\title{
BMJ Open Protocol for the 'Virtual Traveller' cluster-randomised controlled trial: a behaviour change intervention to increase physical activity in primary- school Maths and English lessons
}

\author{
E Norris, ${ }^{1}$ S Dunsmuir, ${ }^{2}$ O Duke-Williams, ${ }^{3}$ E Stamatakis, ${ }^{1,4,5} \mathrm{~N}$ Shelton ${ }^{1}$
}

To cite: Norris E,

Dunsmuir S, Duke-

Williams 0, et al. Protocol for the 'Virtual Traveller' clusterrandomised controlled trial: a behaviour change intervention to increase physical activity in primaryschool Maths and English lessons. BMJ Open 2016;6: e011982. doi:10.1136/ bmjopen-2016-011982

- Prepublication history and additional material is available. To view please visit the journal (http://dx.doi.org/ 10.1136/bmjopen-2016011982).

Received 19 March 2016 Revised 6 June 2016 Accepted 7 June 2016

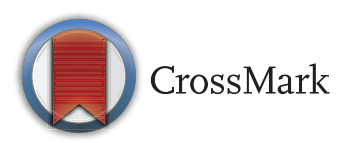

For numbered affiliations see end of article.

Correspondence to

E Norris;

e.norris.11@ucl.ac.uk

\section{ABSTRACT}

Introduction: Physical activity (PA) has been shown to be an important factor for health and educational outcomes in children. However, a large proportion of children's school day is spent in sedentary lessontime. There is emerging evidence about the effectiveness of physically active lessons: integrating physical movements and educational content in the classroom. 'Virtual Traveller' is a novel 6-week intervention of 10-min sessions performed 3 days per week, using classroom interactive whiteboards to integrate movement into primary-school Maths and English teaching. The primary aim of this project is to evaluate the effect of the Virtual Traveller intervention on children's PA, on-task behaviour and student engagement.

Methods and analysis: This study will be a clusterrandomised controlled trial with a waiting-list control group. Ten year 4 (aged 8-9 years) classes across 10 primary schools will be randomised by class to either the 6-week Virtual Traveller intervention or the waiting-list control group. Data will be collected 5 times: at baseline, at weeks 2 and 4 of the intervention, and 1 week and 3 months postintervention. At baseline, anthropometric measures, 4-day objective PA monitoring (including 2 weekend days; Actigraph accelerometer), PA and ontask behaviour observations and student engagement questionnaires will be performed. All but anthropometric measures will be repeated at all other data collection points. Changes in overall PA levels and levels during different time-periods (eg, lessontime) will be examined. Changes in on-task behaviour and student engagement between intervention groups will also be examined. Multilevel regression modelling will be used to analyse the data. Process evaluation will be carried out during the intervention period. Ethics and dissemination: The results of this study will be disseminated through peer-review publications and conference presentations. Ethical approval was obtained through the University College London Research Ethics Committee (reference number: 3500-004).

\section{Strengths and limitations of this study}

- Use of objective monitoring to assess physical activity (PA).

- Assessment of PA and educational outcomes.

- Intervention developed with teachers according to National Curriculum teaching objectives.

- Use of self-selected participation from teachers and classes.

- Blinding of participants and experimenter not possible due to novel nature of intervention.

\section{INTRODUCTION}

Physical activity (PA) in children has been linked to a range of positive health outcomes, including improved cardiometabolic profiles $^{1}{ }^{2}$ and motor skills. ${ }^{3} \mathrm{PA}$ has also been shown to improve educational outcomes, such as on-task behaviour, ${ }^{4}$ cognitive function $^{5}$ and academic achievement. ${ }^{6}$ However, despite these wide-ranging benefits, children currently spend around 8.6 hours a day in sedentary activities, ${ }^{7}$ found to be negatively associated with health ${ }^{8}$ and educational outcomes. $^{9}$ Obligatory seated classroom lessons are an important contributor to this typically sedentary lifestyle. As $\mathrm{PA}^{10}$ and sedentary behaviour levels ${ }^{11}$ have been found to track into adulthood, it is vital that active habits are facilitated as much as possible during childhood.

Although schools and teachers are obliged by the National Curriculum ${ }^{12}$ and OFSTED assessments ${ }^{13}$ to facilitate $\mathrm{PA}$ and overall health and well-being, a lack of time is typically cited by teachers as the primary barrier for PA provision. ${ }^{14}$ As such, interventions have attempted to make educational time more physically active via physically active lessons. ${ }^{15}$ These integrate educational 
content with physical movements in the classroom environment: allowing curriculum and health objectives to be simultaneously addressed. ${ }^{16}$ Physically active lessons are distinct from 'activity-breaks' or 'brain-breaks' which provide bouts of classroom-based PA without educational content. ${ }^{17}$ Examples of physically active lesson programmes include Take $10 !^{18}$ and Physical Activity Across the Curriculum (PAAC) $:{ }^{19}$ largely limited to American populations.

A recent systematic review of emerging physically active lesson research ${ }^{15}$ found increased light and moderate-to-vigorous physical activity (MVPA) levels, ${ }^{19} 20$ on-task behaviour ${ }^{21}$ and academic achievement. ${ }^{19}$ The increasing body of evidence shows the benefits of physically active lessons across PA and educational outcomes, indicating physically active lessons as a promising new teaching method. ${ }^{22}$ However, this existing evidence-base has mostly assessed PA during the school day only and featured limited sample sizes. ${ }^{15}$ Despite being relatively novel interventions, reporting of intervention details in physically active lesson research is often poor, preventing replication in research and educational contexts. ${ }^{15}$ The effects of physically active lessons on student engagement, an essential precursor for learning reflecting an individual's behaviours and cognitions related to learning and the school environment, ${ }^{23}{ }^{24}$ has not yet been assessed. Physically active lesson research has also not used available classroom technology of interactive whiteboards, ${ }^{25}$ used to deliver educational content in over $70 \%$ of UK classrooms. ${ }^{26}$

The Virtual Traveller intervention was developed to address these identified issues. It provides 10-min sessions of physically active Virtual Field Trips (VFTs) for teachers to deliver via the class interactive whiteboard during Maths and English teaching. VFTs allow classes to explore preselected locations around the world, using their movements to simulate interaction with and travel to destinations. ${ }^{25}$ The Virtual Traveller intervention has been developed following mixed-methods feasibility work. A one-off VFT pilot intervention comparing a physically active VFT with a sedentary version found significantly reduced sedentary time and increased light and MVPA time in active VFT students. ${ }^{25}$ A qualitative feasibility study of teacher interviews and student focus groups found positive perceptions of active VFTs as a fun, simple and inclusive method of combining movement and teaching. ${ }^{27}$

\section{Hypotheses and aims}

Following previous evidence into physically active lessons and a pilot study, ${ }^{25}$ we hypothesise that the Virtual Traveller intervention will: (1) increase children's time in light PA and MVPA and reduce sedentary time during the school day, (2) increase children's time in light PA and MVPA and reduce sedentary time during lessontime and (3) improve on-task behaviour during lessontimes. The primary aim of the study is to evaluate the provision of the Virtual Traveller intervention on children's PA, on-task behaviour and student engagement.

\section{METHODS AND ANALYSIS}

\section{Study design}

Virtual Traveller is a 6-week classroom-based physically active lesson intervention. It will be evaluated using a cluster-randomised controlled trial with a waiting-list control group. The waiting-list control group will be provided with the full programme of Virtual Traveller sessions after the final data collection period. Data collection will take place on a rolling basis from March 2015 until May 2016. Baseline data collection will take place before classes are randomised by computer programme ${ }^{27}$ by the first author to either intervention or waiting-list control groups. Data will be collected twice during the 6-week intervention period at weeks 2 and 4 and twice at 1-week and 3-month follow-up (figure 1).

\section{Recruitment and study participants}

Ten state-funded primary schools from in and around Greater London will be recruited by the first author to participate in the Virtual Traveller study. One year 4 (aged 8-9 years) class from each school will participate, with the Virtual Traveller programme content developed around Maths and English National Curriculum for this year-group. Single classes across multiple schools will be recruited, as adding sites (schools in this study) is more consequential for multilevel modelling (MLM) power than adding participants per site. ${ }^{28}$ Schools will be recruited via (1) Public Health and School Sports organisations in boroughs across Greater London and (2) via social media participant calls from the study's developed Twitter account. These recruitment approaches will be used as a very low follow-up rate $(20 \%)$ was experienced by approaching schools on an individual basis via email in the previous pilot study. ${ }^{25}$

Following initial expressed interest, a face-to-face visit will be organised to explain the study details to participating head-teachers and teachers before schools give their final agreement to participate. To recruit children into the study, the lead researcher (EN) will deliver a 10-min presentation to participating classes 2 weeks prior to baseline assessment, introducing the Virtual Traveller project, accelerometer devices and benefits of participating. At the end of presentations, participants will be provided with hard copy parent and student information and informed consent sheets and a parent questionnaire to complete and return. To encourage participant retention and accelerometer wear adherence, an ongoing incentive competition will be run within each class. A certificate will be given to the child in each class with the longest accelerometer wear time at each data collection phase. Also, the child in each class with the longest overall wear time across intervention phases will be given a certificate and $£ 10$ activity vouchers for their local leisure centre. To prevent potential 


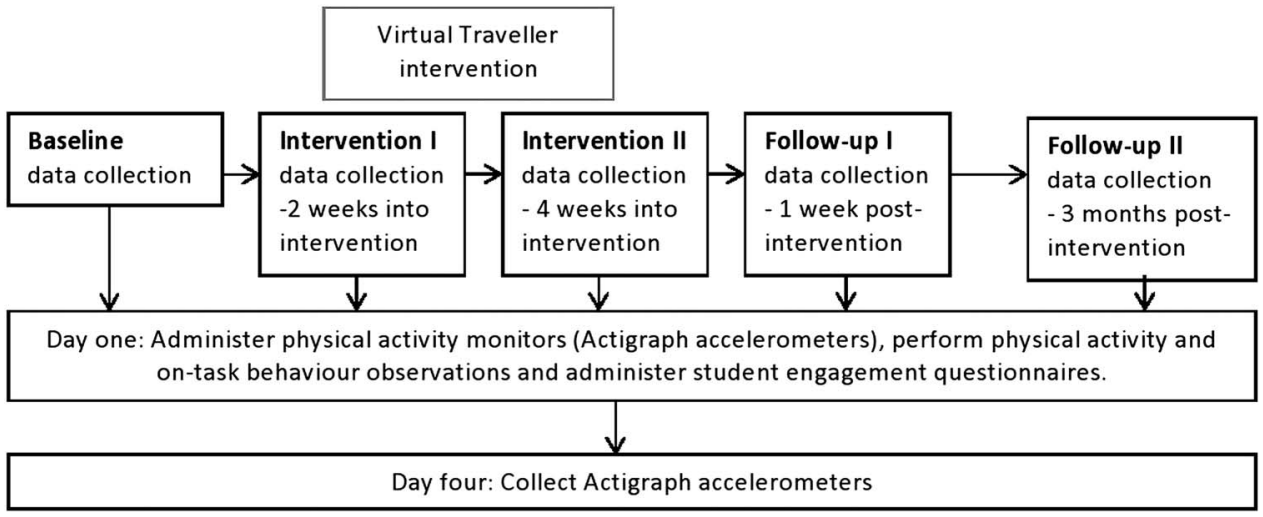

Figure 1 Virtual Traveller intervention study design.

bias from this competition element, the researcher will remind all students at each data collection phase that the prize is based on their wear time alone and not based on how active they are.

\section{Intervention}

The Virtual Traveller programme is designed to be integrated into year 4 National Curriculum Maths and English teaching. ${ }^{12}$ The programme consists of eighteen, 10-min physically active VFT sessions, to be run three times a week over the 6-week intervention period. Nine sessions are based on English and nine on Maths content. Sessions were developed with consultation from 2-year four teachers identified during qualitative feasibility work. ${ }^{27}$ Each session has its own identifying code number, with a summary of all sessions provided in figure 2. Sessions can be run in any order to best suit content being taught by teachers at the time. Sessions can also be run at any point of Maths and English teaching, that is, not restricted to being used as a starter or plenary only. Globe-based movement throughout sessions also makes them highly crosscurricular, ${ }^{12} 27$ combining Maths, English and Geographical content. Qualitative feasibility work identified that the sessions should be provided on simple, familiar software to best facilitate teacher-use. ${ }^{27}$ Virtual Traveller sessions will hence be provided on ubiquitous Microsoft Powerpoint software with embedded Google Earth videos $^{29}$ via USB stick.

Sessions will be delivered using classroom interactive whiteboards. Teachers will stand and lead each session, read included questions and movement prompts, and demonstrate movements. Students will stand behind their desks and complete prompted movements throughout each session. Included Google Earth videos will show transitions between locations on a virtual globe, with accompanying text prompting children to simulate appropriate movements as they 'travel', such as running on-the-spot. Additional images, YouTube videos and sound effects, ${ }^{30}$ were also included to add interest. Detailed overviews of example Maths and English Virtual Traveller sessions are provided in online supplementary appendices A and B.

\section{Teacher training}

Following baseline measurements and randomisation by class, all intervention classroom teachers will be required to attend a 30-min one-on-one training session with the lead researcher. This will be organised according to the teachers' availability, either before school or after school, or during teachers' preparation, planning and assessment time. Training will briefly outline research showing the benefits of child PA on health, education and well-being $(\sim 5 \mathrm{~min})$. Teachers will then be asked to reflect on the extent they integrate PA into their own teaching and discuss their experiences of this $(\sim 5 \mathrm{~min})$. An outline of Virtual Traveller will then be given, detailing the length, intensity and features of the intervention. A sample Virtual Traveller session will be demonstrated by the researcher on their laptop ( $\sim 5 \mathrm{~min})$. The process evaluation $\log$ sheet will then be introduced: requiring teachers to record which Virtual Traveller sessions they run, when and their perceived success out of 5 . Teachers will be requested to complete the log immediately after each session to minimise forgetting. Finally, a Virtual Traveller Guide will be introduced and provided for teachers to use as a reference document during the intervention ( $\sim 5 \mathrm{~min})$. This includes brief information on how to access the Virtual Traveller sessions, a brief summary of all sessions and description of physical activities included and an answer key for questions included within sessions. The researcher will also discuss the teacher's upcoming short-term and medium-term planning to see how the Virtual Traveller programme could best be imbedded into their Maths and English teaching ( $10 \mathrm{~min})$. Email and telephone contact details for the researcher will be given to support all teachers with intervention or measurement procedure queries during the study. Face-to-face support for teachers will also be provided during data collection visits.

\section{Procedures}

Data collection procedures will take place over 3 months in each participating class. The lead researcher will collect data on a date convenient to each class teacher. Data collection sessions will last $\sim 20$ minutes. 


\begin{tabular}{|c|c|}
\hline Maths & English \\
\hline $\begin{array}{l}\text { M1: Tens and Hundreds Challenge } \\
\text { Pupils use their movements to show multiplications and divisions by tens } \\
\text { and hundreds. }\end{array}$ & $\begin{array}{l}\text { E1: Kung Fu Punctuation } 1 \text { (White Belt) } \\
\text { Visit China for your Kung Fu Punctuation training. Use Kung Fu moves to } \\
\text { represent appropriate punctuation in example sentences. }\end{array}$ \\
\hline $\begin{array}{l}\text { M2: Maths Marching } \\
\text { Practice times tables and angles whilst marching for the Queen's Trooping } \\
\text { the Colour. Choose the times table appropriate for your class. }\end{array}$ & $\begin{array}{l}\text { E2: Kung Fu Punctuation } 2 \text { (Black Belt) } \\
\text { Add some more complex punctuation to your Kung-Fu Punctuation } \\
\text { repertoire, before a freestyle session. }\end{array}$ \\
\hline $\begin{array}{l}\text { M3: Maths: True or False? } \\
\text { Use movements to show if you think statements related to Maths are true } \\
\text { or false. }\end{array}$ & $\begin{array}{l}\text { E3: English: True or False? } \\
\text { Pupils use movements to show if you think statements related to English } \\
\text { are true or false. }\end{array}$ \\
\hline $\begin{array}{l}\text { M4: London } 2012 \text { Olympics and beyond } \\
\text { Explore the London Olympic park and the future of the Olympics. Count } \\
\text { and time the actions of famous Olympians whilst simulating their actions. }\end{array}$ & $\begin{array}{l}\text { E4: Explanation Texts } \\
\text { Pupils show their understanding of explanation text features using } \\
\text { movements. }\end{array}$ \\
\hline $\begin{array}{l}\text { M5: Metric Movements } \\
\text { Practice metric measurements using movements to answer length, weight } \\
\text { and capacity questions. }\end{array}$ & $\begin{array}{l}\text { E5: Mystery Monsters } \\
\text { You are given adjectives to an imaginary monster. Pupils use movements } \\
\text { to show how they think the monster would move and act. }\end{array}$ \\
\hline $\begin{array}{l}\text { M6: Sports Galore } \\
\text { Practice addition, multiplication and subtraction using sports movements. }\end{array}$ & $\begin{array}{l}\text { E6: Noun Reverse Charades } \\
\text { The class use movements to act out a mystery word for one pupil to } \\
\text { guess. }\end{array}$ \\
\hline $\begin{array}{l}\text { M7: Rock around the Clock } \\
\text { Learn how to use different periods of time from seconds to millennia } \\
\text { using movements. }\end{array}$ & $\begin{array}{l}\text { E7: Persuasive Writing } \\
\text { The class use movements to show their understanding on the features of } \\
\text { persuasive writing. }\end{array}$ \\
\hline $\begin{array}{l}\text { M8: Money, Money, Money! } \\
\text { Practice calculations with money using movements to show the answers. }\end{array}$ & $\begin{array}{l}\text { E8: Frozen Vocabulary } \\
\text { Practice your class' own target spellings to practice definitions and } \\
\text { spelling to movement. 'Frozen' as in freezing your movements-not the } \\
\text { movie! *requires spellings to have been set* }\end{array}$ \\
\hline $\begin{array}{l}\text { M9: Global Dance Count } \\
\text { Count how many target moves you do to dance crazes. }\end{array}$ & $\begin{array}{l}\text { E9: Apostrophes \& Plurals } \\
\text { Pupils use movements to indicate where apostrophes should go in } \\
\text { possessive and plural sentences. }\end{array}$ \\
\hline
\end{tabular}

Figure 2 Summary of Virtual sessions.

Anthropometric assessments will be taken at baseline only, taking an additional $10 \mathrm{~min}$. Objective devices (accelerometers) will be given to children to monitor their PA behaviour as soon as they arrive at school on the first day of each data collection phase. It is recommended that accelerometers are worn for at least 4 days to provide a reliable estimate of children's habitual PA. ${ }^{31}$ Devices will hence be provided to participating children for four full days (2 weekdays and 2 weekend days) at each data collection phase and to capture school-time and leisure-time activity. Trained researchers will observe children's PA and on-task behaviour during Virtual Traveller sessions (in intervention students only) or typical teaching (control students and intervention students during baseline and follow-up assessments). A student engagement questionnaire will be provided to students. On day 4, participants will return the device to the lead researcher at school. This process will be repeated at all data collection points.

After baseline assessments, cluster randomisation of classes to intervention or waiting-list control groups will be done via computer programme. ${ }^{32}$ Randomisation will continue until five intervention classes and five control classes are allocated. Waiting-list control classes will continue to receive their normal teaching during the study: receiving teacher training and the full intervention on USB stick after the final data collection point.

\section{Use of behaviour change theory and techniques}

As identified in the aforementioned systematic review, ${ }^{15}$ physically active lesson research has been largely atheoretical to date. This study embeds the COM-B model $^{33}$ (figure 3) to increase children's PA during lesson-time and beyond. The key COM-B model cognitions of Capability, Opportunity and Motivation are applied within the Virtual Traveller intervention context to maximise PA behaviour change. As the provision of physically active lessons is ultimately the decision of the teacher, it is important that such interventions address teacher cognitions specifically. First, teachers' capability to integrate activity into teaching will be addressed in this study via teacher training: planning how and when Virtual Traveller sessions will be integrated into Maths and English teaching. Head-teacher support will also be secured via a face-to-face meeting with the researcher to ensure teachers' capability is supported at an institutional level. Second, teachers' opportunity to teach physically active lessons must be increased. Virtual Traveller will provide this by physically supplying relevant, readymade teaching resources and ensuring activities are suitable given class space restrictions. Teacher's motivation to teach physically active lessons will be addressed by

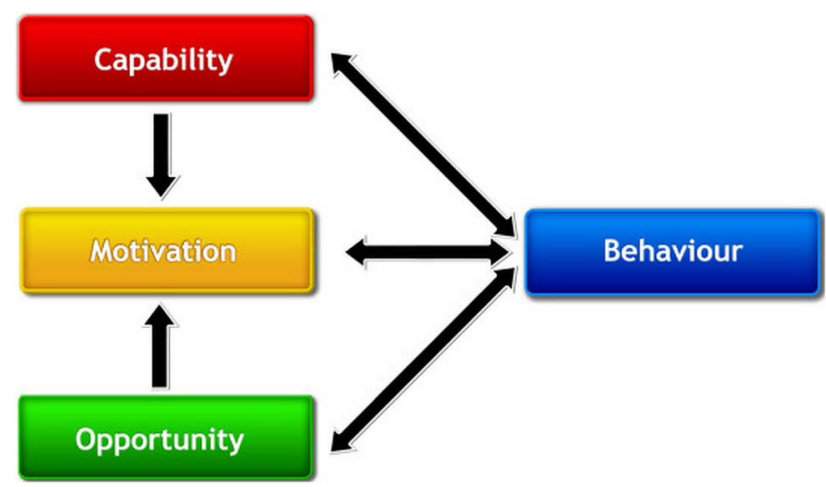

Figure 3 COM-B model. 
providing Virtual Traveller sessions that are quick to run, ${ }^{14}$ provided on familiar Powerpoint software ${ }^{27}$ and produce visible activity and educational benefits to students.

As identified in the aforementioned systematic review, ${ }^{15}$ specific reporting of physically active lesson intervention details to date has been mostly weak. By reporting the exact nature and content of these novel interventions in a standardised way, studies can be more accurately compared and replicated. ${ }^{34}$ To aid replication of the Virtual Traveller intervention, the Behaviour Change Techniques (BCTs) embedded into the intervention and its procedures are reported according to the Behaviour Change Technique Taxonomy V.1 (BCTTv1). ${ }^{35}$ BCTs represent the 'active ingredients' of interventions influencing behaviour change in participants. ${ }^{36}$ The BCTs embedded during teacher training and the intervention itself are listed in figure 4. For example, during teacher training, the researcher will work with participating teachers to formulate action plans (BCT 1.4) on how they would integrate the three Virtual Traveller sessions each week into their Maths and English teaching. During the intervention, a Virtual Traveller-branded teacher $\log$ will be placed on the wall by the teacher's computer as a prompt (BCT 7.1) to remind them to run the Virtual Traveller sessions.

\section{Measurement and instruments Anthropometric}

At baseline, weight will be assessed by the researcher to the nearest $0.1 \mathrm{~kg}$ (Weight Watchers 8961U electronic scales, Milton Keynes, UK) and height to the nearest $\mathrm{mm}$ (2 $\mathrm{m}$ tape measure). Body mass index (BMI; $\mathrm{kg} / \mathrm{m}^{2}$ ) will be produced from these measurements, to allow assessments of potential differential effects of the Virtual Traveller intervention between BMI categories. Underweight, overweight and obesity prevalence will be estimated using the 2nd, 85th and 95th centiles of the 1990 UK reference curves. ${ }^{37}$

\section{Accelerometer}

Accelerometers are recognised to provide the most valid and reliable measurement of children's PA. ${ }^{31}$ This study will use Actigraph GT1M accelerometers: wearable motion sensors that measure movement across X- and Y-axes and provide date and time-stamped data on activity duration and intensity throughout the day. These devices have been identified as having acceptable validity and reliability in children. ${ }^{38}$ Objective PA monitoring has been successfully used in other physically active lesson interventions. ${ }^{19} 39$ The Actigraph will be attached to an adjustable elastic belt and worn on the child's right hip. Accelerometers will be activated at 09:00 on day 1 when accelerometers are distributed at the start of school and deactivated at 23:59 on day 4. This will provide a total of 86 hours maximum wear time for each data collection phase. Children will be asked to wear the device during waking hours every day for four consecutive days, but not during water-based activities or sleep to limit device damage and participant discomfort.

\section{Observations}

Pilot work identified a need for additional PA measurements in active VFT sessions. Although children were physically observed by teachers and researchers to be highly active during a one-off active VFT session, Actigraph GT1M accelerometer output recorded the majority of session time as sedentary. ${ }^{25}$ Accelerometers

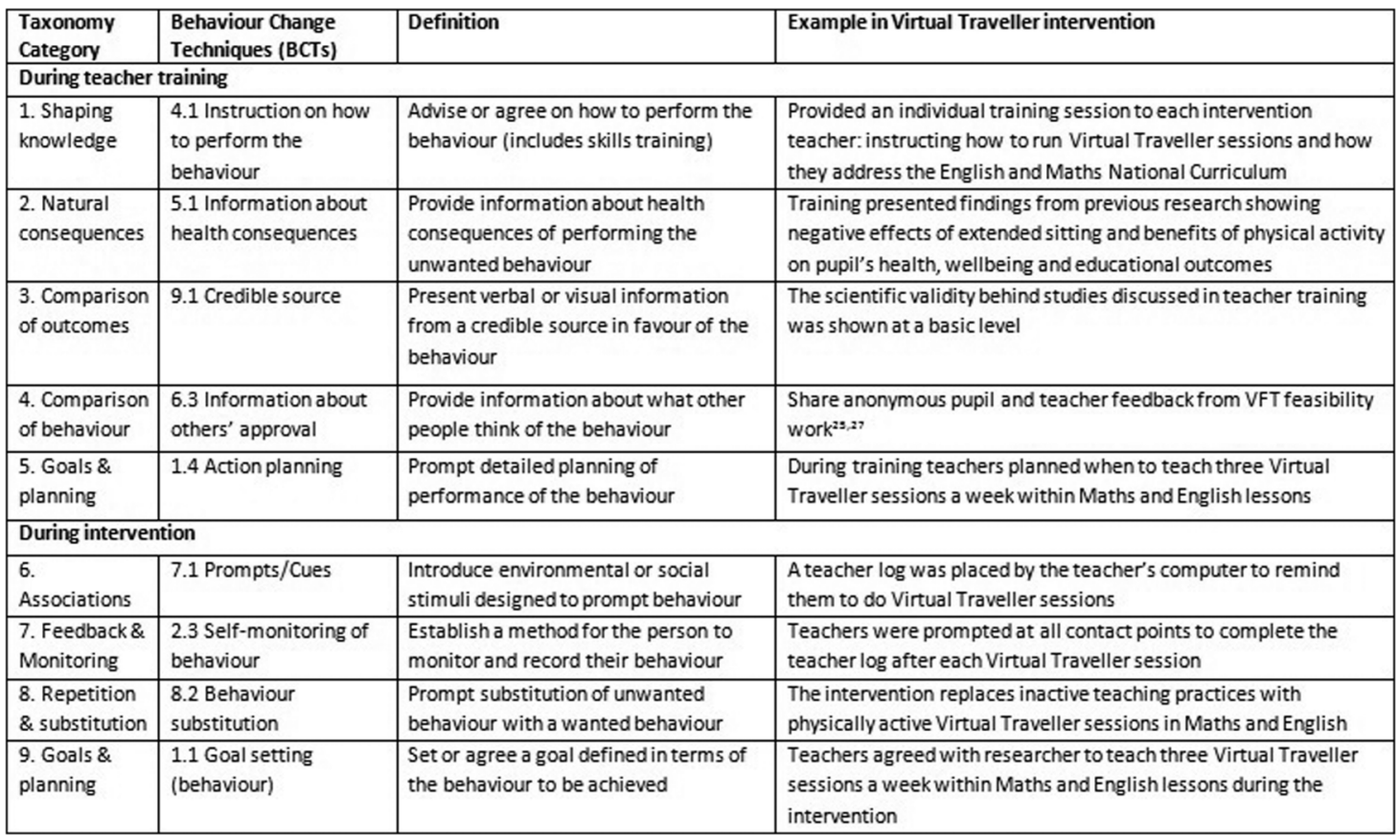

Figure 4 Behaviour Change Techniques embedded into Virtual Traveller intervention and teacher training. 
have weaker sensitivity to non-ambulatory, on-the-spot movements such as those elicited by VFT sessions, compared to accelerating, travelling movements such as running. ${ }^{40}$ Triangulation of accelerometers with other PA measurement methods seems appropriate. Physical activity observations are recognised as a useful validation technique for controlled activity situations. ${ }^{41}$ The Children's Activity Rating Scale (CARS) ${ }^{42}$ will be used to code observed PA behaviour during Virtual Traveller and control sessions. This defines observed activities into five intensity categories: stationary, stationary with limb or trunk movements, slow movement, moderate movement and fast movement. CARS has previously been triangulated with objective data in other child-based studies. ${ }^{43} 44$

On-task behaviour during Virtual Traveller and control sessions will be assessed using the Observing Teacher and Pupils in Classrooms (OPTIC) tool. ${ }^{45}$ This rates behaviour as on-task (making eye contact with teacher or task, following teacher's instructions) or off-task. Observations similar to OPTIC have been previously used to assess on-task behaviour in physically active lesson interventions. ${ }^{2146}$

Both tools will be applied in the same observations to reduce researcher and class burden. Two VFT (intervention group) or two typically taught Maths or English lessons (control group) will be observed for each class. Teachers will provide researchers with a class seating plan featuring participant numbers to enable identification during each observation. Sessions will be observed for 20-min periods using a monetary time sampling technique. Participating students will be observed in turn for $4 \mathrm{~s}$ before the next child is observed, with data recorded on a standardised score sheet. To allow inter-rater reliability of both measures, one session in each class ( $\mathrm{N}=10 ; 20 \%$ of all observations) will be observed by two researchers. An observer training session will be run in a baseline session to assess absolute agreement in interrater reliability of both measures.

\section{Questionnaires}

Parents will be provided with a hard copy demographic questionnaire along with their informed consent documents. This will take $\sim 5$ min to complete and contains questions on the child's sex, ethnicity, English language status, disability status and free school meal status and family income.

Student engagement will be assessed in children at each data collection point using the Student Engagement Instrument-Elementary Version (SEI-E), ${ }^{47}$ a primary-school version of the well-validated School Engagement Instrument (SEI). ${ }^{48}{ }^{49}$ The SEI-E features 24 items assessed on 4-point Likert scales, ranging from strongly disagree to strongly agree. It takes $15-20 \mathrm{~min}$ to administer and assesses four constructs of student engagement: Teacher-Student Relationships, Peer Support for Learning, Family Support for Learning and Future Goals and Aspirations. ${ }^{47}$ The SEI-E is a relatively new instrument, to date only validated in its original sample $(\mathrm{n}=1943) ;{ }^{47}$ however, few other tools are available to assess student engagement in primary-school ages. $^{24} 48$ As previous research has shown student engagement to be more accurately reported by students themselves rather than teacher proxy reports, ${ }^{50}$ it seemed appropriate to use a direct student questionnaire measure. Teachers, teaching assistants and research staff will assist students in completing the questionnaire.

\section{Process evaluation}

The overall feasibility of the Virtual Traveller intervention and its implementation will be assessed via a process evaluation within all intervention classes. ${ }^{51}$ This will be based around the RE-AIM framework to assess: Reach, Effectiveness, Adoption, Implementation and Maintenance. ${ }^{52}{ }^{53}$ First, teachers will be provided with a Virtual Traveller log sheet to record which sessions they run, when and the perceived success of the session out of 5 . Teachers will be requested to complete the $\log$ immediately after each session to minimise forgetting. Second, a process evaluation questionnaire will be provided to students and teachers at weeks 2 and 4 of the 6-week intervention. Providing these questionnaires on two occasions will allow any potential change in satisfaction during the intervention to be recorded. Six questions of 5-point Likert scales will be used in each questionnaire. Example items include 'I liked being physically active during the Virtual Traveller programme' for students and 'Virtual Traveller sessions that I have run have met appropriate learning outcomes' for teachers. The student questionnaire will also feature the one-item pictorial Children's OMNI scale of perceived exertion $^{54}$ to assess perceived physical effort during Virtual Traveller sessions. Student and teacher questionnaires also contained two questions for free-text responses: 'What do you like about Virtual Traveller?' and 'What do you not like about Virtual Traveller?' Finally, teacher interviews and student focus groups will be run after the intervention period. Student focus groups and teacher interviews will last around 15-min, use semistructured questions and be audio-recorded and transcribed by the lead researcher. For student focus groups, one mixed sex group of six students per class will take part. Each teacher will be asked to select two children of lower, middle and higher overall academic ability, as done in previous physically active lesson evaluation. ${ }^{55}$ Questions will explore students' perceptions and enjoyment of Virtual Traveller sessions, examples of memorable sessions and potential improvements. Teacher interviews will be arranged according to teacher availability. Questions will investigate teacher perceptions of Virtual Traveller sessions compared to typical Maths and English teaching. Perceived effects of Virtual Traveller on children's PA and educational outcomes will be explored, as well as challenges to implementing the programme. 


\section{ANALYSIS}

\section{Outcomes}

The primary outcome for this study will be the change in average daily time spent in MVPA as recorded by the Actigraph accelerometer. Secondary outcomes assessed via accelerometers, observations and student questionnaires will include (1) changes in daily time spent in light, moderate and vigorous lesson-time PA, (2) changes in lesson-time spent in light, moderate and vigorous lesson-time PA, (3) changes in on-task behaviour during lesson-time and (4) change in student engagement.

\section{Quantitative analysis}

Raw data will be extracted from each Actigraph accelerometer and analysed using ActiLife software. To maximise the study sample, participants will be included in analysis if they provide at least 1 day of valid accelerometer wear time, including one Virtual Traveller day in intervention students. Sensitivity analysis will be carried out to compare results if a minimum of 3-day valid accelerometry data are included. Valid accelerometer wear time will be defined as at least 500 min wear time between 07:00 and 00:00. This replicates criteria previously used in research utilising The International Children's Accelerometry Database (ICAD),${ }^{2}$ the world's largest resource of pooled child accelerometer data. Data will be collected in $5 \mathrm{~s}$ epochs ${ }^{31}$ and analysed using Pulsford cut-points ${ }^{56}$ to classify activity as sedentary: ( $<100$ counts per minute, CPM), light (100-2240 CPM), moderate (2241-3840 CPM) or vigorous ( $\geq 3841 \mathrm{CPM})$. As per methods followed in the International Children's Accelerometry Database, non-wear will be defined as $60 \mathrm{~min}$ of consecutive zeros, allowing for $2 \mathrm{~min}$ of non-zero interruptions. ${ }^{57}$ MLM will be used to reflect the hierarchical relationships between students and schools (one class tested in each school) ${ }^{58}$ Three-level multilevel models will be developed to assess the differences in outcomes between time-point (Level 1), pupils (Level 2) and classes (Level 3). All authors will have access to the final trial data set.

\section{Sample size calculations}

Sample size calculations were run to assess the number of students and classes needed to detect changes in the primary outcome of accelerometer-assessed PA in CPM. The Optimal Design MLM sample size calculation programme was used (Raudenbush SW. Optimal Design Software for Multi-level and Longitudinal Research. Version 3.01, 2011). Considering available resources, it was initially decided that a maximum of 10 classes could be recruited. Settings for the power calculations reflected those used in other physically active lesson research. ${ }^{39}$ Calculations were based on baseline post-test correlation scores of $r=0.30,{ }^{39} 80 \%$ power, $\alpha$ levels set at $\mathrm{p}<0.05$, a conservative intraclass correlation coefficient $(\mathrm{ICC}=0.15)$ and a maximum class cluster of $\mathrm{J}=10$. It was calculated that a study sample of $n=140$ with 10 clusters (ie, classes) of 14 students providing valid accelerometry data will be needed to provide sufficient power to detect a between-intervention group difference.

\section{DISCUSSION}

\section{Strengths and limitations}

Strengths of this study include its use of objective monitoring to assess PA, its assessment of PA and educational outcomes and its teacher-supported programme development. A limitation of this study is its reliance on selfselected participation from teachers and classes. This may limit the applicability of findings to wider teaching environments.

\section{Ethical consideration and dissemination}

Teachers of each participating class will be asked to provide written consent for their schoolchildren to participate in the study. The researcher will then deliver a 10-min session to classes 2 weeks prior to baseline assessment, introducing the Virtual Traveller project and accelerometer devices. All parents of children in participating classes will then be asked to provide written consent for their child to participate. Children will also be provided with age-appropriate consent information. Participants will be identified by participant number only and can withdraw from the study at any time. Data will be only collected in students with completed consent forms; however, all students in each intervention classroom will take part in Virtual Traveller sessions. A 10-min debriefing session will be provided by the researcher in each class after the final data collection phase. Unintended and adverse effects will be assessed within process evaluation assessment. Permission for any important protocol modifications will be sought by the ethics committee and reported to trial participants and in subsequent publications.

The findings from this study will first be disseminated to Public Health and School Sports organisations contacted during recruitment. Second, we will also disseminate to social media channels via the developed Virtual Traveller Twitter account. Finally, we will disseminate to academic researchers and policymakers via academic conference presentations and journal articles.

\section{Author affiliations}

${ }^{1}$ Department of Epidemiology \& Public Health, University College London, London, UK

${ }^{2}$ Department of Clinical, Educational and Health Psychology, University College London, London, UK

${ }^{3}$ Department of Information Studies, University College London, London, UK ${ }^{4}$ Charles Perkins Centre, Prevention Research Collaboration, School of Public Health, Sydney Medical School, University of Sydney, Sydney, New South Wales, Australia

${ }^{5}$ Faculty of Health Sciences, University of Sydney, Sydney, New South Wales, Australia

Twitter Follow Emma Norris at @EJ_Norris

Contributors EN, SD, OD-W, ES and NS made substantial contributions to the concept and design of the study. EN drafted the manuscript and SD, OD-W, ES and NS critically revised it. 
Funding This work was supported by a UCL Crucible doctoral studentship held by EN (grant number 509180). ES is funded by the National Health and Medical Research Council through a Senior Research Fellowship.

Competing interests None declared.

Patient consent Obtained.

Ethics approval Ethical approval was obtained through the University College London Research Ethics Committee (reference number 3500-004).

Provenance and peer review Not commissioned; externally peer reviewed.

Open Access This is an Open Access article distributed in accordance with the Creative Commons Attribution Non Commercial (CC BY-NC 4.0) license, which permits others to distribute, remix, adapt, build upon this work noncommercially, and license their derivative works on different terms, provided the original work is properly cited and the use is non-commercial. See: http:// creativecommons.org/licenses/by-nc/4.0/

\section{REFERENCES}

1. Cesa CC, Sbruzzi G, Ribeiro RA, et al. Physical activity and cardiovascular risk factors in children: meta-analysis of randomized clinical trials. Prev Med 2014;69:54-62.

2. Ekelund U, Luan J, Sherar LB, et al. Moderate to vigorous physical activity and sedentary time and cardiometabolic risk factors in children and adolescents. JAMA 2012;307:704-12.

3. Wrotniak BH, Epstein LH, Dorn JM, et al. The relationship between motor proficiency and physical activity in children. Pediatrics 2006;118:e1758-e65.

4. Mahar MT. Impact of short bouts of physical activity on attention-to-task in elementary school children. Prev Med 2011;52 (Suppl 1):S60-4.

5. Donnely JE, Hillman $\mathrm{CH}$, Castelli $\mathrm{D}$, et al. Physical activity, fitness, cognitive function, and academic achievement in children: a systematic review. Med Sci Sport Sci 2016;48:1197-222.

6. Fedewa AL, Ahn S. The effects of physical activity and physical fitness on children's achievement and cognitive outcomes: a meta-analysis. Res Q Exerc Sport 2011;82:521-35.

7. LeBlanc AG, Katzmarzyk PT, Barreira TV, et al. Correlates of total sedentary time and screen time in 9-11 year-old children around the world: the International Study of Childhood Obesity, Lifestyle and the Environment. PLOS ONE 2015;10:e0129622.

8. Saunders TJ, Chaput JP, Tremblay MS. Sedentary behaviour as an emerging risk factor for cardiometabolic diseases in children and youth. Can J Diabetes 2014;38:53-61.

9. Carson V, Kuzik N, Hunter S, et al. Systematic review of sedentary behavior and cognitive development in early childhood. Prev Med 2015;78:115-22.

10. Telama R. Tracking of physical activity from childhood to adulthood: a review. Obes Facts 2009;2:187-95.

11. Smith L, Gardner B, Hamer M. Childhood correlates of adult TV viewing time: a 32-year follow-up of the 1970 British Cohort Study. $J$ Epidemiol Community Health 2014;69:309-13.

12. Department for Education. The National Curriculum in England: Framework Document. London: Department for Education, 2013.

13. Ofsted. The common inspection framework: education, skills and early years. Manchester: Ofsted, 2015.

14. Naylor PJ, Nettlefold L, Race D, et al. Implementation of school based physical activity interventions: a systematic review. Prev Med 2015;72C:95-115.

15. Norris E, Shelton N, Dunsmuir S, et al. Physically active lessons as physical activity and educational interventions: a systematic review of methods and results. Prev Med 2015;72:116-25.

16. Donnelly JE, Lambourne K. Classroom-based physical activity, cognition, and academic achievement. Prev Med 2011;52(Suppl 1): S36-42.

17. Bartholomew JB, Jowers EM. Physically active academic lessons in elementary children. Prev Med 2011;52(Suppl 1):S51-4.

18. Kibbe DL, Hackett J, Hurley M, et al. Ten Years of TAKE 10! Integrating physical activity with academic concepts in elementary school classrooms. Prev Med 2011:52:S43-50.

19. Donnelly JE, Greene JL, Gibson CA, et al. Physical Activity Across the Curriculum (PAAC): a randomized controlled trial to promote physical activity and diminish overweight and obesity in elementary school children. Prev Med 2009;49:336-41.

20. Erwin HE, Abel MG, Beighle A, et al. Promoting children's health through physically active math classes: a pilot study. Health Promot Pract 2011;12:244-51.
21. Mahar MT, Murphy SK, Rowe DA, et al. Effects of a classroom-based program on physical activity and on-task behavior. Med Sci Sports Exerc 2006;38:2086-94.

22. Mullender-Wijnsma MJ, Hartman E, de Greeff JW, et al. Physically active math and language lessons improve academic achievement: a cluster randomized controlled trial. Pediatrics 2016;137:1-9.

23. Finn JD, Zimmer KS. Student engagement: what is it? Why does it matter? Handbook of Research on Student Engagement. Springer 2012: 97-131.

24. Fredricks J, McColskey W, Meli J, et al. Measuring student engagement in upper elementary through high school: a description of 21 instruments. Washington, DC: Institute of Education Sciences, 2011.

25. Norris E, Shelton N, Dunsmuir S, et al. Virtual Field Trips as physically active lessons for primary-school children: a pilot study. BMC Pub Health 2015;15:366.

26. Futuresource Consulting. Interactive displays quarterly insight: state of the Market report, Quarter 1, 2010.

27. Norris E, Shelton N, Dunsmuir S, et al. Teacher and pupil perspectives on the use of Virtual Field Trips as physically active lessons. BMC Res Notes 2015;8:719.

28. Raudenbush SW, Liu X. Statistical power and optimal design for multisite randomized trials. Psych Methods 2000;5:199.

29. Google. Google Earth 2016. https://www.google.com/earth/.

30. SoundBible. SoundBible.com: Free Sound Clips, Sound Bites and Sound Effects, 2016. http://soundbible.com/.

31. Cain KL, Sallis JF, Conway TL, et al. Using accelerometers in youth physical activity studies: a review of methods. $J$ Phys Act Health 2013;10:437-50.

32. Research Randomizer. Research Randomizer 2014. https://www. randomizer.org/.

33. Michie S, van Stralen MM, West R. The behaviour change wheel: a new method for characterising and designing behaviour change interventions. Implem Sci 2011;6:42.

34. Michie S, Fixsen D, Grimshaw JM, et al. Specifying and reporting complex behaviour change interventions: the need for a scientific method. Implem Sci 2009;4:1-6.

35. Michie S, Richardson M, Johnston M, et al. The behavior change technique taxonomy ( 1 1) of 93 hierarchically clustered techniques: building an international consensus for the reporting of behavior change interventions. Ann Behav Med 2013;46:81-95.

36. Abraham C, Michie S. A taxonomy of behavior change techniques used in interventions. Health Psychol 2008;27:379.

37. Cole TJ, Freeman JV, Preece MA. Body mass index reference curves for the UK, 1990. Arch Dis Child 1995;73:25-9.

38. Kim Y, Beets MW, Welk GJ. Everything you wanted to know about selecting the 'right' Actigraph accelerometer cut-points for youth, but...: a systematic review. J Sci Med Sport 2012;15:311-21.

39. Riley N, Lubans DR, Holmes K, et al. Findings from the EASY minds cluster randomized controlled trial: evaluation of a physical activity integration program for mathematics in primary schools. $J$ Phys Act Health 2015;13:198-206.

40. Trost SG. Objective measurement of physical activity in youth: current issues, future directions. Exerc Sport Sci Rev 2001;29: 32-6.

41. Corder K, Ekelund U, Steele RM, et al. Assessment of physical activity in youth. $J$ Appl Phys 2008;105:977-87.

42. Puhl J, Greaves K, Hoyt M, et al. Children's Activity Rating Scale (CARS): description and calibration. Res $Q$ Exerc Sport 1990;61:26-36.

43. Janssen X, Cliff DP, Reilly JJ, et al. Predictive validity and classification accuracy of ActiGraph energy expenditure equations and cut-points in young children. PLOS ONE 2013;8:e79124.

44. Finn KJ, Specker B. Comparison of Actiwatch activity monitor and Children's Activity Rating Scale in children. Med Sci Sport Exerc 2000;32:1794-7.

45. Merrett $F$, Wheldall K. Observing pupils and teachers in classrooms (OPTIC): a behavioural observation schedule for use in schools. Educ Psychol 1986;6:57-70.

46. Grieco LA, Jowers EM, Bartholomew JB. Physically active academic lessons and time on task: the moderating effect of body mass index. Med Sci Sport Exerc 2009;41:1921-6.

47. Carter CP, Reschly AL, Lovelace MD, et al. Measuring student engagement among elementary students: pilot of the Student Engagement Instrument-Elementary Version. Sch Psychol Q 2012;27:61-73.

48. Appleton JJ, Christenson SL, Kim D, et al. Measuring cognitive and psychological engagement: validation of the Student Engagement Instrument. J Sch Psychol 2006;44:427-45. 
49. Reschly AL, Betts J, Appleton JJ. An examination of the validity of two measures of student engagement. Int J Sch Educ Psychol 2014;2:106-14.

50. Appleton JJ, Lawrenz F. Student and teacher perspectives across mathematics and science classrooms: the importance of engaging contexts. Sch Sci Math 2011;111:143-55.

51. McGraw SA, Sellers D, Stone E, et al. Measuring implementation of school programs and policies to promote healthy eating and physical activity among youth. Prev Med 2000;31:S86-97.

52. McGoey T, Root Z, Bruner MW, et al. Evaluation of physical activity interventions in children via the reach, efficacy/effectiveness, adoption, implementation, and maintenance (RE-AIM) framework: a systematic review of randomized and non-randomized trials. Prev Med 2016;82:8-19.

53. Glasgow RE, Vogt TM, Boles SM. Evaluating the public health impact of health promotion interventions: the RE-AIM framework. Am J Public Health 1999;89:1322-7.
54. Robertson RJ, Goss FL, Boer NF, et al. Children's OMNI scale of perceived exertion: mixed gender and race validation. $\mathrm{Med} S \mathrm{Ci}$ Sports Exerc 2000;32:452-8.

55. Riley N, Lubans DR, Morgan PJ, et al. Outcomes and process evaluation of a programme integrating physical activity into the primary school mathematics curriculum: the EASY Minds pilot randomised controlled trial. J Sci Med Sport 2015;18:656-61.

56. Pulsford RM, Cortina-Borja M, Rich C, et al. Actigraph accelerometer-defined boundaries for sedentary behaviour and physical activity intensities in 7 year old children. PLOS ONE 2011;6: e21822.

57. Sherar L, Griew P, Esliger D, et al. Internatioal Children's Acelerometry Database (ICAD): design and methods. BMC Public Health 2011;11:485.

58. Campbell MK, Mollison J, Steen N, et al. Analysis of cluster randomized trials in primary care: a practical approach. Fam Pract 2000;17:192-6. 